\title{
Primary Headache in Yemen: Prevalence and Common Medications Used
}

\author{
Salah A. Abdo, ${ }^{1,2}$ Mohammed Amood AL-Kamarany, ${ }^{1,2}$ Karem H. Alzoubi, ${ }^{3}$ \\ Mohamed T. Al-Maktari, ${ }^{4}$ and Abdulrhman H. Al-Baidani ${ }^{1}$ \\ ${ }^{1}$ Department of Pharmacy Practice, Faculty of Clinical Pharmacy, Hodeidah University, P.O. Box 3114, Hodeidah, Yemen \\ ${ }^{2}$ Tihama Foundation for Drug Studies and Research, Hodeidah, Yemen \\ ${ }^{3}$ Department of Clinical Pharmacy, Faculty of Pharmacy, Jordan University of Science and Technology, P.O. Box 3030, \\ Irbid 22110, Jordan \\ ${ }^{4}$ Department of Medical Parasitology, Faculty of Medicine and Health Sciences, Sana'a University, P.O. Box 2289, Sana'a, Yemen
}

Correspondence should be addressed to Salah A. Abdo; salah292006@hotmail.com

Received 25 July 2014; Accepted 7 October 2014; Published 5 November 2014

Academic Editor: Changiz Geula

Copyright (C) 2014 Salah A. Abdo et al. This is an open access article distributed under the Creative Commons Attribution License, which permits unrestricted use, distribution, and reproduction in any medium, provided the original work is properly cited.

\begin{abstract}
Background and Objective. Primary headaches is a major medical concern in certain Arabic countries, for example Oman, Jordan, and Qatar. This study was aimed at increasing understanding of the prevalence of headache in Arabic countries and identifying common medications used for treatment because of the lack of research done in this field in Yemen. Methods. This is a cross-sectional observational study conducted by recruiting case-series of adults and elderly who have primary headache within the age group from 18 to 85 years. 12640 subjects received a simple explanation for the aim of the study as ethical issue. The subjects were allowed to complete a self-conducted screening questionnaire. The data were diagnosed according to the International Headache Society's diagnostic criteria (2004). Results. The results showed that $76.5 \%$ of the primary headache is prevalent at least once per year, $27.1 \%$ of the tension type headache (TTH) was the maximum percentage of type of headache, and $14.48 \%$ of the migraine headache (MH) was the minimum percentage. On the other hand, the relationship between the primary headache and age of subjects was statistically significant $(P<0.05)$, while between primary headache and sex was not $(P>0.05)$. In addition, $70.15 \%$ of the subjects said that headache attacks affected their activity of daily livings (ADL). $62.26 \%$ of the subjects used the medications without medical advice regarding their headache. $37.73 \%$ of the subjects relied on medical professionals (physicians and pharmacist) regarding analgesics use. The most common agent used among the medications was paracetamol (38.4\%). Others included ibuprofen, aspirin, diclofenac sodium, naproxen, mefenamic acid, ergotamine and (11.45\%) were unknown agents. Conclusion. We concluded that absence of health attention from the Yemeni Community and education from the health system in the country regarding analgesics use and their potential risk led to abuse of such medications and could be a reason beyond high prevalence of headache in Yemen.
\end{abstract}

\section{Introduction}

Headache can be defined as prevalent and disabling condition affecting people in all age groups worldwide, resulting in low job performance and quality of life with a significant economic burden on societies [1]. Headache gains attention worldwide because it is a common discomfort making to the top ten list of complaints in ambulatory medical care [2] and has a low healthcare and public profile [3]. Moreover primary headaches rank among the most common and disabling disorders worldwide [4].
The impact of headache is incredible, for example, in children, one of the causes that result in absence from school and interfering with other daily activities $[5,6]$. On the other hand, in elders the incidence of most primary headache may decline after $55-60$ years of age $[7,8]$. The prevalence of primary headache in certain studies in adults over 18 years accounts for about $6.4 \%$ of the population $[9,10]$. If we go further toward Asia, one study mentioned that the prevalence of migraine is between 1 and $22 \%$ and that is lower than that reported for North America and Europe [11]. Furthermore, there is a lack in epidemiology of headache disorders in 
Asia [11]. In addition, there is an overuse for analgesics and that may be the cause beyond the high prevalence in certain Middle East areas such as Oman, Qatar, and Jordan where there is high prevalent self-medicating for headache [12, 13] because the overuse of such analgesics can lead to overuse syndrome $[14,15]$.

Several studies of prevalence of primary headaches in Arabic countries were conducted, for example, Saudi Arabia, Qatar, Oman, Bahrain, United Arab Emirates, Kuwait, and Jordan [2]. The major objective of our study is to help in understanding of distribution of primary headaches in Arab area and correlate with age and gender. In addition, to estimate the common medications used by Yemeni people.

\section{Materials and Methods}

2.1. Study Design. This is a cross-sectional observational study conducted by recruiting case-series of adults and elderly who have primary headache within the age group from 18 to 85 years. Subjects with primary headache received a simple explanation for the aim of the study as an ethical issue. If they agreed, the subject was interviewed. Confidentiality of the collected data was achieved by keeping data record in a locked room with limited access to the research team only.

2.2. Subjects and Questionnaire. The study included 12640 subjects from four Yemeni governorates that were selected to estimate the one-year overall prevalence in Yemen; they include Sana', Taiz, Al-Hodeidah, and Thamar. Subjects were approached at their work places, classes, or homes and selected in random manner. The study was conducted from July 2010 to September 2011. The study was carried out by using the principles described in the Declaration of Helsinki, including all amendments and revisions. Every subject was asked to complete a self-conducted questionnaire in the presence of the researcher to answer any inquiries and then reviewed immediately to detect and prevent any errors. Researchers interviewed illiterate subjects to complete the questionnaire. The questionnaire gathered information that included demographic data, family history, frequency and type of headache, and its impact on everyday activities, medications use, consultation regarding medication increasing with time, and frequency of headache after medication usage. The data were diagnosed according to the International Headache Society's diagnostic criteria [16].

2.3. Data Analysis. Statistical Package for the Social Sciences version 16.0 (SPSS Inc., Chicago, IL, USA) and Excel software version 2010 were used for data analysis. The descriptive analysis (\%) and Chi-square test were used to make comparisons among categorical variables. For all statistical analyses, a $P$ value of less than 0.05 was considered statistically significant.

\section{Results}

3.1. Demographic Characteristics of Subjects. The sample was of subjects $(n=12640)$ that were selected from four
TABle 1: Demographic data $(n=12640)$.

\begin{tabular}{|c|c|c|}
\hline Characteristic & $n$ & $\%$ \\
\hline \multicolumn{3}{|l|}{ Gender } \\
\hline Male & 8562 & 67.7 \\
\hline Female & 4078 & 32.26 \\
\hline \multicolumn{3}{|l|}{ Age (years) } \\
\hline $18-29$ & 8754 & 69.25 \\
\hline $30-39$ & 2404 & 19.01 \\
\hline $40-49$ & 962 & 7.61 \\
\hline$\geq 50$ & 520 & 4.11 \\
\hline \multicolumn{3}{|l|}{ Education } \\
\hline Illiterate & 570 & 4.5 \\
\hline Elementary school & 394 & 3.11 \\
\hline Secondary school & 975 & 7.71 \\
\hline High school & 4281 & 33.86 \\
\hline Diploma & 2053 & 16.2 \\
\hline University student & 1136 & 8.98 \\
\hline B.A. & 2407 & 19.04 \\
\hline M.S. & 752 & 5.94 \\
\hline Ph.D. & 72 & 0.56 \\
\hline \multicolumn{3}{|l|}{ Nationality } \\
\hline Yemeni & 12492 & 98.8 \\
\hline Arab & 146 & 1.15 \\
\hline Foreign & 2 & 0.016 \\
\hline \multicolumn{3}{|l|}{ Marital status } \\
\hline Single & 7283 & 57.6 \\
\hline Married & 5084 & 40.2 \\
\hline Other & 273 & 2.2 \\
\hline \multicolumn{3}{|l|}{ Monthly income } \\
\hline Low (<232\$ US) & 9318 & 73.7 \\
\hline Medium (232-462\$ US) & 2594 & 20.5 \\
\hline $\operatorname{High}(>462 \$$ US $)$ & 728 & 5.7 \\
\hline \multicolumn{3}{|l|}{ Smoking } \\
\hline Smoker & 2945 & 23.3 \\
\hline Nonsmoker & 9695 & 76.7 \\
\hline
\end{tabular}

different governorates of Yemen within the age group from 18 to 85 years. The sample of study was represented in the males $67.7 \%$ while in the females it was $32.3 \%$. As shown in Table $1,33.8 \%$ of the subjects were high school graduates followed by bachelor degree holders (19\%), diploma holders (16.24\%), university students (8.98\%), secondary school graduates (7.7\%), master's degree holders $(5.9 \%)$, and Ph.D. degree holders (0.56\%). $98.8 \%$ were Yemeni people. $57.6 \%$ were singles and $40.2 \%$ were married. $23.3 \%$ were smokers and $76.7 \%$ were nonsmokers.

3.2. Prevalence of Primary Headache. The primary headache was found in $76.6 \%(n=9684)$; the characteristics of patients were shown in Table 2 . Two types of primary headache were observed in this study, tension type-headache (TTH) was $27.10 \%$, and migraine headache $(\mathrm{MH})$ was $14.50 \%$, while unknown type was $35.01 \%$. However, this difference between types of headache was statistically significant $(P<0.05)$. 
TABLE 2: Family history, frequency and type of headache.

\begin{tabular}{lcc}
\hline Variable & $n$ & $\%$ \\
\hline Headache frequency $(n=12640)$ & 1087 & 8.6 \\
Daily & 2737 & 21.6 \\
Fewer than daily to weekly & 2998 & 23.7 \\
Fewer than weekly to monthly & 2862 & 22.6 \\
Fewer than monthly to 1 year & 2956 & 23.4 \\
No headache & & \\
Headache affects daily activities $(n=9684)$ & 7286 & 70.2 \\
Yes & 2398 & 29.8 \\
No & & \\
Other family members complaining from headaches & & \\
(n $=12640)$ & 1006 & 7.9 \\
Father & 1956 & 15.50 \\
Mother & 1527 & 12.10 \\
Brothers or sisters & 2342 & 18.50 \\
Other relatives & 1269 & 10.39 \\
More than one family member & 1584 & 12.50 \\
None & 2956 & 23.40 \\
No headache & & \\
Type of headache $(n=12640)$ & 1831 & 14.50 \\
Migraine & 3427 & 27.10 \\
Tension & 4426 & 35.01 \\
Unknown & 2956 & 23.40 \\
No headache & & \\
\hline
\end{tabular}

On the other hand, the relationship between the primary headache and age of subjects was found and was statistically significant $(P<0.05)$, while the relationship between primary headache and sex was not $(P>0.05)$ (Table 3$)$. In addition, the higher frequency of TTH and $\mathrm{MH}$ was in adults between 18 and 29 years (76.85\% and $70.30 \%$, resp.), and the lower frequency was in elderly more than 50 years $(4.20 \%$ and $4.40 \%$, resp.). Also, $70.15 \%$ of the subjects said that headache affected their activity of daily livings (ADL), and $64.1 \%$ had positive family history of headache.

3.3. Common Medication Used. The use, abuse, and incidence of medications in 9684 patients with primary headache were studied. The common medications used for headache were paracetamol (38.4\%), ibuprofen (16.7\%), aspirin (19.7\%), diclofenac sodium $(7.5 \%)$, naproxen $(2.5 \%)$, mefenamic acid (2.2\%), ergotamine (1.5\%), and unknown (11.5) (Figure 1). In other meaning, $88.5 \%$ of medications were known by their users, while $11.5 \%$ were unknown. Furthermore, majority of subjects $(62.26 \%)$ used the medications without medical advice and few of them did (37.73\%). In addition $64.8 \%$ of subjects depend on family to get medications while $35.16 \%$ depend on physicians and pharmacists. $8.75 \%$ of patients used analgesics on daily basis, fewer than daily to weekly was $24.58 \%$, fewer than weekly to monthly was $27.90 \%$, fewer than monthly to one year was $24.79 \%$, and patients who never use analgesics was $13.90 \%$. In addition, $77.57 \%$ of subjects showed increased headache frequency on medication use, while $22.42 \%$ did not (Table 4 ).

\section{Discussion}

The overall one year period prevalence of primary headaches among adults in Yemen was estimated for the first time. About $76.6 \%$ of subjects complained from primary headache at least once per year. Primary headache included two types, migraine and tension-type headache. The prevalence in this study was much higher comparing with average global prevalence of headache $(46 \%)[11,17]$. Similar results were reported in Arabic countries, namely, Oman and Qatar [18, 19]. Also, the same results were recorded in non-Arabic countries, namely, Northern Finland and Singapore [2023]. In addition, previous study was reported in Oman that showed a prevalence of headache of about $45 \%$ [24]; however, that study was among university medical students and not the general population. Other studies were performed in Arabic countries that showed high prevalence, except Saudi Arabia in which the prevalence of primary headache is ranged from 8 to $12 \%[19,25,26]$, which was much lower than that reported in all other studies from the Middle East area, while in Jordan the prevalence of primary headache was also higher than overall global prevalence [2].

On the other hand, Table 5 showed that TTH was more prevalent than that of $\mathrm{MH}(27.10 \%$ and $14.5 \%$, resp.) and it was within the prevalence range reported from studies conducted in the Middle East area (3.1-36.1\%) [3, 18, 24, 27, 28]. Furthermore, our study was in concordance with other studies in Middle East area that showed that prevalence for tension-type headache was lower than its global prevalence (about $42 \%$ ) [11], which seems to be the case for the whole Middle East area. Concerning MH, the prevalence in our study was higher than that showed in Arabic countries which was falls within 10 to $12.2 \%$ [18, 28, 29]. One study in Qatar showed that the prevalence was $7.9 \%$. In our study, the prevalence of $\mathrm{MH}$ was higher than the global $\mathrm{MH}$ prevalence (11.2\%) [17], and in Western Europe (14\%) [18] which was very close to that in our study [17]. Therefore, Yemen seems to have higher migraine prevalence than many other parts of the world.

In agreement with Alzoubi et al. [2], the family history of headaches was found in most of the subjects. Furthermore, ADL was affected more significantly than in that study, $70.1 \%$ and $51.6 \%$, respectively. About $62.26 \%$ of our sample did not seek medical advice regarding their headaches.

The most common medication used in Yemen was paracetamol. Same result obtained from Jordan, where the only study discussed this issue. In addition most users in Jordan, rely on recommendations from non-medical advisers (the family members), this in agreement with Alzoubi et al with exception that usually users rely on friends rather than family members but both indicating a lack of communication with health professionals, physicians and pharmacists. In the same study the causes beyond popularity of paracetamol could be due to its availability as an over-the-counter medication, 
TABLE 3: Prevalence of migraine and tension-type headache according to ages and gender $(n=5258)$.

\begin{tabular}{|c|c|c|c|c|c|c|c|c|c|c|c|c|c|c|}
\hline \multirow{3}{*}{$\begin{array}{l}\text { Type } \\
\text { Gender } \\
\text { Age }\end{array}$} & \multicolumn{7}{|c|}{ TTH } & \multicolumn{7}{|c|}{$\mathrm{MH}$} \\
\hline & \multicolumn{2}{|c|}{ Male } & \multicolumn{2}{|c|}{ Female } & \multicolumn{2}{|c|}{ Total } & \multirow{2}{*}{$P$ value } & \multicolumn{2}{|c|}{ Male } & \multicolumn{2}{|c|}{ Female } & \multicolumn{2}{|c|}{ Total } & \multirow{2}{*}{$P$ value } \\
\hline & $n$ & $\%$ & $n$ & $\%$ & $n$ & $\%$ & & $n$ & $\%$ & $n$ & $\%$ & $n$ & $\%$ & \\
\hline $18-29$ & 1278 & 37.3 & 1434 & 41.8 & 2712 & 76.85 & \multirow{5}{*}{$P<0.05^{*}$} & 641 & 35.1 & 644 & 35.2 & 1285 & 70.30 & \multirow{5}{*}{$P<0.05^{*}$} \\
\hline $30-39$ & 226 & 6.60 & 174 & 5.10 & 400 & 11.70 & & 191 & 10.4 & 137 & 7.5 & 328 & 17.90 & \\
\hline $40-49$ & 52 & 1.50 & 119 & 3.50 & 171 & 5.0 & & 78 & 4.3 & 59 & 3.2 & 137 & 7.50 & \\
\hline$\geq 50$ & 59 & 1.70 & 85 & 2.50 & 144 & 4.2 & & 53 & 2.9 & 28 & 1.5 & 81 & 4.40 & \\
\hline Total & 1615 & 47.10 & 1812 & 52.90 & 3427 & 100 & & 963 & 52.7 & 868 & 47.4 & 1831 & 100 & \\
\hline
\end{tabular}

${ }^{*}$ The relationship between the primary headache and age of subjects was statistically significant $(P<0.05)$, while the relationship with sex was not statistically significant $(P>0.05)$. TTH: tension-type headache; MH: migraine headache.

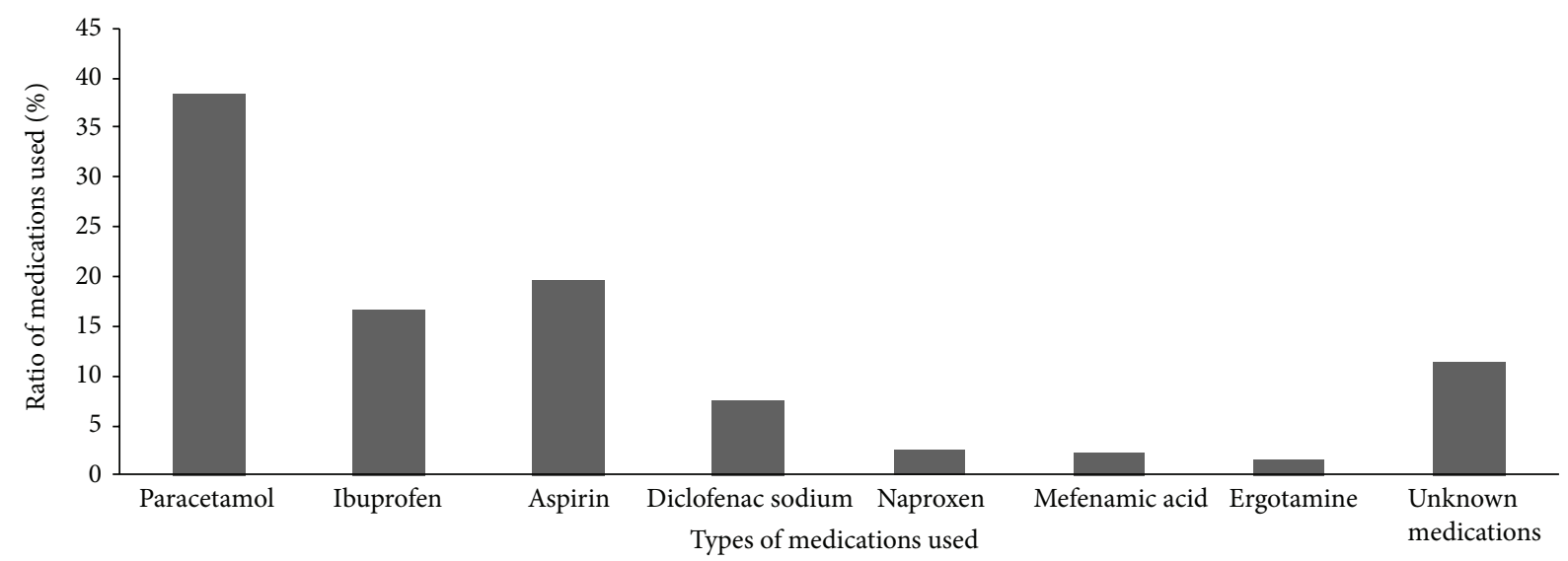

Figure 1: Medications use among headache patients $(n=10996)$. Note: some patients use different medications at an increase of headache frequency.

TABLE 4: Approach to medication use among headache patients.

\begin{tabular}{lcc}
\hline Variable & $n$ & $\%$ \\
\hline Nonadvice medical help for headaches $(n=9684)$ & & \\
$\quad$ Nonadvice & 6030 & 62.26 \\
$\quad$ Advice & 3654 & 37.73 \\
Advice on using analgesics $(n=3654)$ & & \\
$\quad$ Physician & 993 & 27.71 \\
$\quad$ Pharmacist & 2661 & 72.82 \\
Medications usage $(n=9684)$ & & \\
$\quad$ Daily & 848 & 8.75 \\
$\quad$ Fewer than daily to weekly & 2381 & 24.58 \\
$\quad$ Fewer than weekly to monthly & 2702 & 27.90 \\
$\quad$ Fewer than monthly to 1 year & 2401 & 24.79 \\
$\quad$ No use & 1347 & 13.90 \\
Increase in headache frequency after analgesic use & & \\
$\quad$ Yes & 2172 & 22.42 \\
$\quad$ No & 7512 & 77.57 \\
Increase analgesic dose used over time & & \\
$\quad$ Yes & 3335 & 34.34 \\
No & 6349 & 65.56 \\
\hline
\end{tabular}

TABLE 5: Prevalence of TTH and MH in Arab countries.

\begin{tabular}{|c|c|c|c|}
\hline Country & Prevalence of Headache (\%) & TTH (\%) & $\mathrm{MH}(\%)$ \\
\hline Our study $^{\mathrm{a}}$ & 76 & 27.10 & 14.50 \\
\hline Jordan $^{\mathrm{b}}$ & 82.3 & 36.1 & 7.7 \\
\hline $\mathrm{Oman}^{\mathrm{c}}$ & 83.6 & - & 10.1 \\
\hline Qatar ${ }^{\mathrm{d}}$ & 72.5 & 11.2 & 7.9 \\
\hline Saudi Arabia ${ }^{\mathrm{e}}$ & $8-12$ & $3.1-9.5$ & $2.6-5$ \\
\hline \multicolumn{4}{|c|}{$\begin{array}{l}\text { TTH, tension type headache; } \mathrm{MH} \text {, migraine headache. } \\
\text { a Adult population ( } \geq 18 \text { years old) for } 24 \text {-month prevalence. }\end{array}$} \\
\hline $\begin{array}{l}{ }^{b} \text { Adult population ( } \geq 18 \text { years old) for } 24 \text {-month prevalence. } \\
{ }^{c} \text { Population ( }>10 \text { years old) for } 24 \text {-month prevalence. }\end{array}$ & \multicolumn{3}{|c|}{$\begin{array}{l}{ }^{\mathrm{d}} \text { Adult population ( }>15 \text { years old) for } 3 \text {-month prevalence. } \\
\text { e All population for } 6 \text {-month prevalence. }\end{array}$} \\
\hline
\end{tabular}

low price, and its safety and less side effects profile on the gastrointestinal tract [2].

The percentage of non-smokers was $76.7 \%$ and smokers was $23.3 \%$ that was lower than in Jordan and surrounding countries reported smoking prevalence of about $26-48 \%$ [3033]. In agreement, our prevalence of smoking falls within the overall prevalence of smoking among adult males and females (21 to $37 \%$ ) in the high-income countries and low to middle income countries (8.9 to 49\%) [34]. Also, in agreement with 
other studies conducted in Arabic area the prevalence of headache is more in female than in male and the prevalence tended to be higher in younger patients below the age of 40 $[19,20]$.

\section{Conclusion}

In conclusion, $76.5 \%$ of our subjects have headache attacks at least once per year indicating that headache that is a major health problem in Yemen. In addition, young adults were the most affected especially by TTH. Absence of health attention and education regarding analgesic use led to abuse of such medications and could be one of the reasons beyond development of headache and this is why Arabic countries have the greatest prevalence of headaches. On the other hand, the educational programs should be planned and implemented to ensure safe practices and to limit random usage of analgesics and encourage population to seek for medical advice before administration.

\section{Conflict of Interests}

The authors declare that there is no conflict of interests regarding the publication of this paper.

\section{Acknowledgments}

The authors would like to thank Belal Fadhel, Aqeel Fadhel, Mohammed Alraimi, Shoa’a Qahtan, Mohammed Al-Antary, Afrah Al-Gunaid, Yasmine Al-Arasi, Katebah Al-Alawi, Abdulwhhab Al-Aromah, Abdullah Shani, Abdullah AlZubaidy, and Yahya Alruaani for their help in data entry.

\section{References}

[1] P. Bahrami, H. Zebardast, M. Zibaei, M. Mohammadzadeh, and N. Zabandan, "Prevalence and characteristics of headache in Khoramabad, Iran,” Pain Physician, vol. 15, no. 4, pp. 327-332, 2012.

[2] K. H. Alzoubi, N. Mhaidat, S. Al Azzam et al., "Prevalence of migraine and tension-type headache among adults in Jordan," The Journal of Headache and Pain, vol. 10, no. 4, pp. 265-270, 2009.

[3] H. T. S. Benamer, D. Deleu, and D. Grosset, "Epidemiology of headache in Arab countries," Journal of Headache and Pain, vol. 11, no. 1, pp. 1-3, 2010.

[4] J. Pascual, "Prevalence of primary headaches: it is not the behavior, but still we have to pay attention to it!", The Journal of Headache and Pain, vol. 12, no. 2, pp. 139-140, 2011.

[5] M. L. Hämäläinen, K. Hoppu, and P. Santavuori, "Pain and disability in migraine or other recurrent headaches as reported by children," European Journal of Neurology, vol. 3, no. 6, pp. 528-532, 1996.

[6] D. Annequin, B. Tourniaire, and H. Massiou, "Migraine and headache in childhood and adolescence," Pediatric Clinics of North America, vol. 47, no. 3, pp. 617-631, 2000.

[7] R. B. Lipton, W. F. Stewart, and K. R. Merikangas, "Reliability in headache diagnosis," Cephalalgia, vol. 13, no. 12, pp. 29-33, 1993.

[8] P. Tanganelli, "Secondary headaches in the elderly," Neurological Sciences, vol. 31, no. 1, pp. 73-76, 2010.
[9] S. Solomon and K. G. Cappa, "The headache of temporal arteritis," Journal of the American Geriatrics Society, vol. 35, no. 2, pp. 163-165, 1987.

[10] C. Lisotto, F. Mainardi, F. Maggion, and G. Zanchin, "Headache in Sturge-Weber syndrome: a case report and review of the literature," Cephalalgia, vol. 24, no. 11, pp. 1001-1004, 2004.

[11] L. J. Stovner, K. Hagen, R. Jensen et al., "The global burden of headache: a documentation of headache prevalence and disability worldwide," Cephalalgia, vol. 27, no. 3, pp. 193-210, 2007.

[12] L. N. Oates, M. J. Scholz, and M. J. Hoffert, "Polypharmacy in a headache centre population," Headache, vol. 33 , no. 8, pp. 436438, 1993.

[13] F. D. Sheftell, "Role and impact of over-the-counter medications in the management of headache," Neurologic Clinics, vol. 15, no. 1, pp. 187-198, 1997.

[14] D. Deleu, Y. Hanssens, and E. A. Worthing, "Symptomatic and prophylactic treatment of migraine: a critical reappraisal," Clinical Neuropharmacology, vol. 21, no. 5, pp. 267-279, 1998.

[15] A. H. Elkind, "Drug abuse and headache," Medical Clinics of North America, vol. 75, no. 3, pp. 717-732, 1991.

[16] Headache Classification Subcommittee of the International Headache Society, "The international classification of headache disorders: 2nd edition," Cephalalgia, vol. 24, supplement 1, pp. 9-160, 2004.

[17] L. J. Stovner and K. Hagen, "Prevalence, burden, and cost of headache disorders," Current Opinion in Neurology, vol. 19, no. 3, pp. 281-285, 2006.

[18] D. Deleu, M. A. Khan, and T. A. H. Al Shehab, "Prevalence and clinical characteristics of headache in a rural community in Oman," Headache, vol. 42, no. 10, pp. 963-973, 2002.

[19] A. Bener, "Frequency of headache and migraine in Qatar," Neuroepidemiology, vol. 27, no. 2, pp. 61-66, 2006.

[20] K.-H. Ho and B. K. C. Ong, "Headache characteristics and race in Singapore: results of a randomized national survey," Headache, vol. 41, no. 3, pp. 279-284, 2001.

[21] R. Nikiforow, "Headache in a random sample of 200 persons: a clinical study of a population in Northern Finland," Cephalalgia, vol. 1, no. 2, pp. 99-107, 1981.

[22] B. K. Rasmussen, R. Jensen, M. Schroll, and J. Olesen, "Epidemiology of headache in a general population-a prevalence study," Journal of Clinical Epidemiology, vol. 44, no. 11, pp. 1147-1157, 1991.

[23] J.-A. Zwart, G. Dyb, T. L. Holmen, L. J. Stovner, and T. Sand, "The prevalence of migraine and tension-type headaches among adolescents in Norway. The Nord-Trøndelag Health Study (Head-HUNT-Youth), a large population-based epidemiological study," Cephalalgia, vol. 24, no. 5, pp. 373-379, 2004.

[24] D. Deleu and Y. Hanssens, "Primary chronic daily headache: clinical and pharmacological aspects. A clinic-based study in Oman," Headache, vol. 39, no. 6, pp. 432-436, 1999.

[25] S. Al-Rajeh, O. Bademosi, H. Ismail, and A. Awada, "Headache syndromes in the eastern province of Saudi Arabia," Headache, vol. 30, no. 6, pp. 359-362, 1990.

[26] M. Abduljabbar, A. Ogunniyi, S. Al Balla, S. Alballaa, and A. AlDalaan, "Prevalence of primary headache syndrome in adults in the Qassim region of Saudi Arabia," Headache, vol. 36, no. 6, pp. 385-388, 1996.

[27] M. A. Jabbar and A. Ogunniyi, "Sociodemographic factors and primary headache syndromes in a Saudi community," Neuroepidemiology, vol. 16, no. 1, pp. 48-52, 1997. 
[28] D. Deleu, M. A. Khan, H. Humaidan, Z. Al Mantheri, and S. Al Hashami, "Prevalence and clinical characteristics of headache in medical students in Oman," Headache, vol. 41, no. 8, pp. 798804, 2001.

[29] S. T. Jamal, P. N. Sharma, F. A. Ramadan, and F. S. Boshehri, "Headache and blood pressure in primary health care setting in Kuwait," Saudi Medical Journal, vol. 25, no. 12, pp. 1849-1854, 2004.

[30] W. Maziak, "Smoking in Syria: profile of a developing Arab country," International Journal of Tuberculosis and Lung Disease, vol. 6, no. 3, pp. 183-191, 2002.

[31] W. Maziak, F. Mzayek, and A. V. Devereaux, "The dynamics of cigarette smoking during military service in Syria," International Journal of Tuberculosis and Lung Disease, vol. 5, no. 3, pp. 292-296, 2001.

[32] R. M. Youssef, S. A. Abou-Khatwa, and H. M. Fouad, "Prevalence of smoking and age of initiation in Alexandria, Egypt," Eastern Mediterranean Health Journal, vol. 8, no. 4-5, pp. 626637, 2002.

[33] Y. S. Khader and A. A. Alsadi, "Smoking habits among university students in Jordan: prevalence and associated factors," Eastern Mediterranean Health Journal, vol. 14, no. 4, pp. 897904, 2008.

[34] K. Slama, "Global perspective on tobacco control. Part I. The global state of the tobacco epidemic," International Journal of Tuberculosis and Lung Disease, vol. 12, no. 1, pp. 3-7, 2008. 


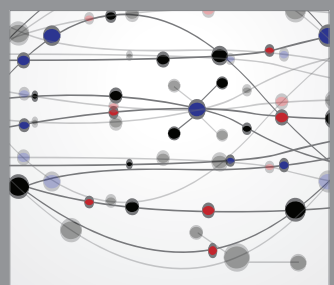

The Scientific World Journal
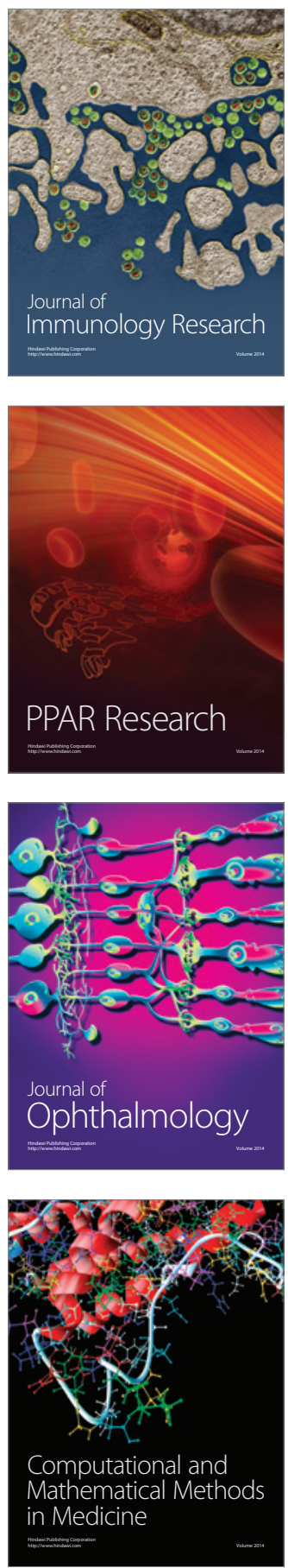

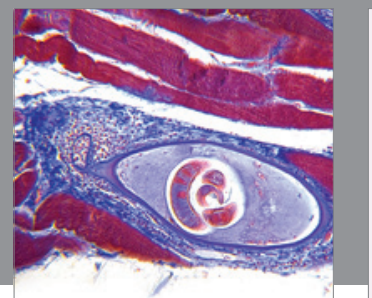

Gastroenterology

Research and Practice
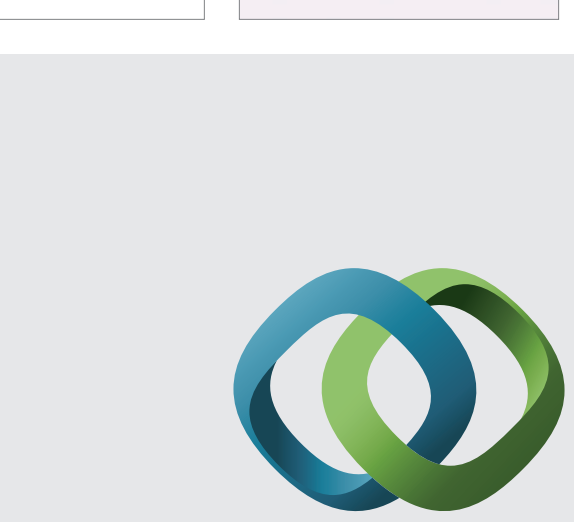

\section{Hindawi}

Submit your manuscripts at

http://www.hindawi.com
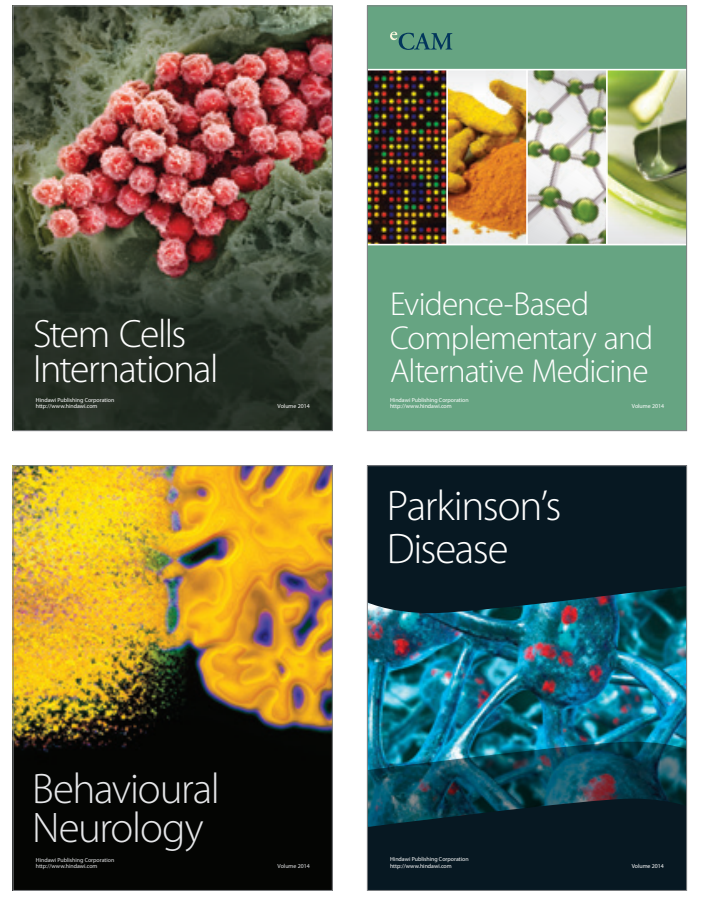
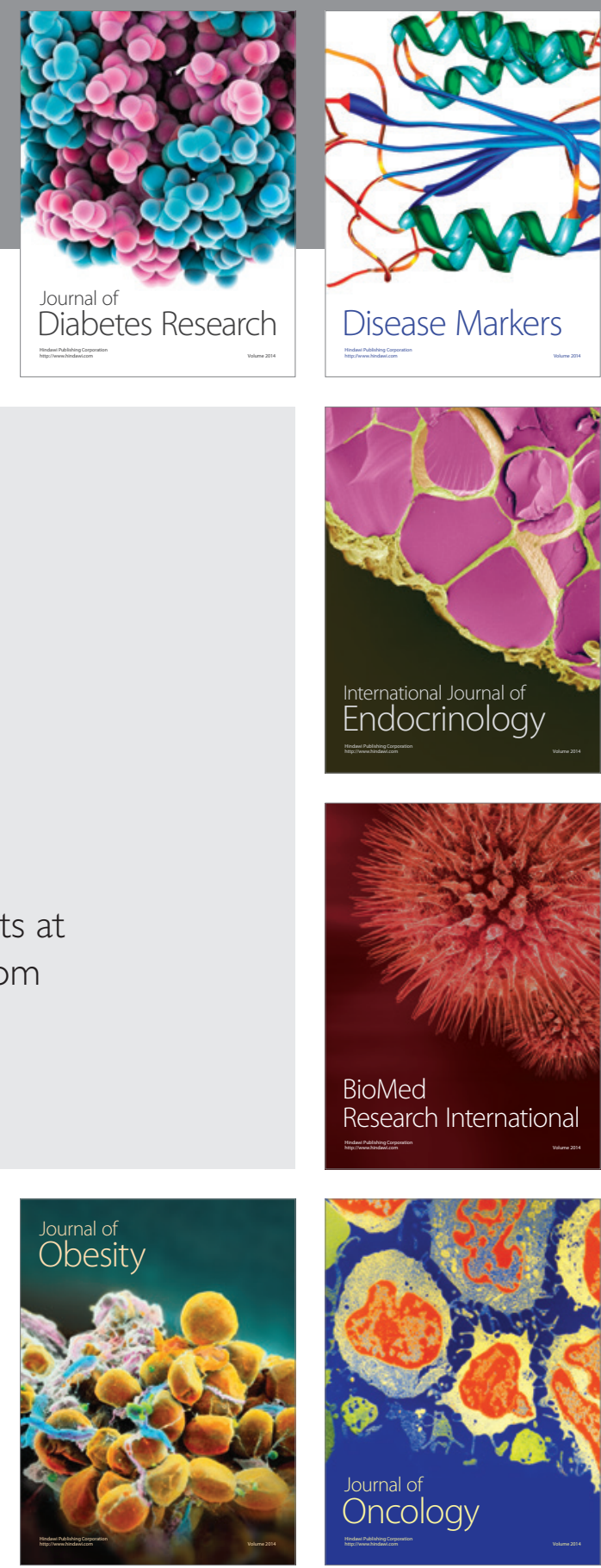

Disease Markers
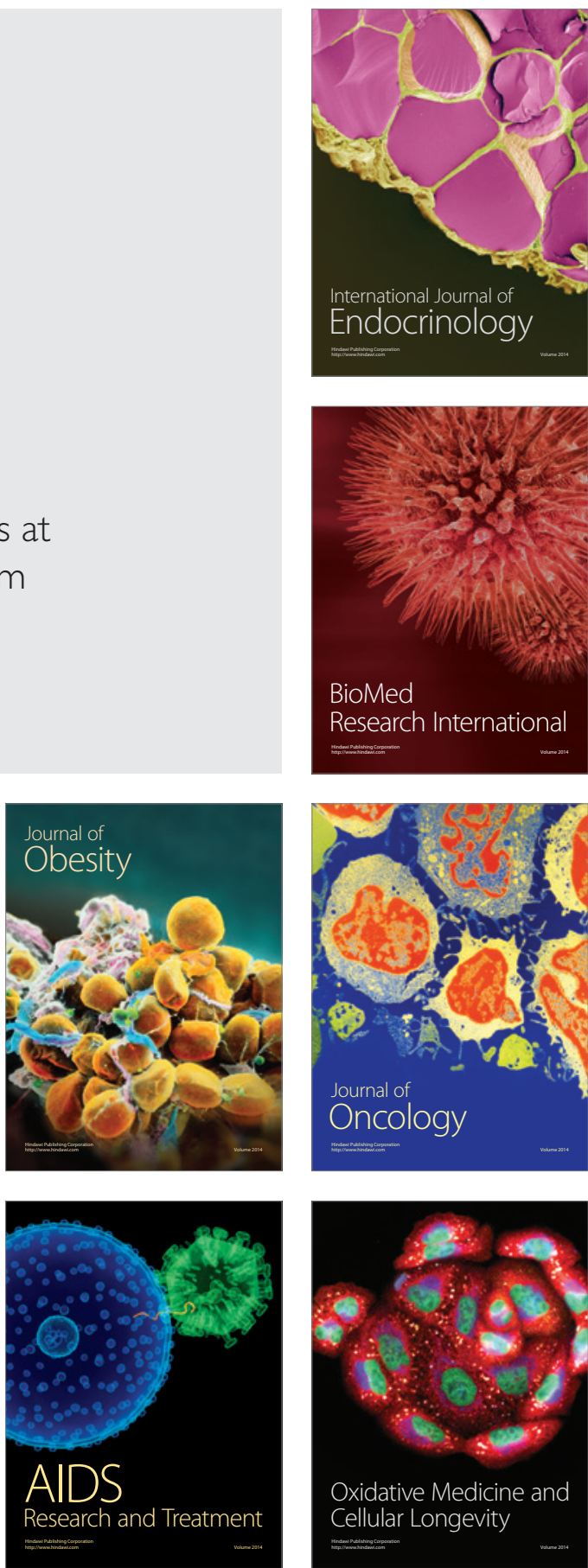